\title{
Response of herbivorous fishes to crown-of-thorns starfish Acanthaster planci outbreaks. I. Substratum analysis and feeding ecology of Acanthurus nigrofuscus and Scarus frenatus
}

\author{
Anthony M. Hart ${ }^{1,2, *}$, David W. Klumpp ${ }^{1}$ \\ ${ }^{1}$ Australian Institute of Marine Science, PMB No. 3, Townsville M.C., Queensland 4810, Australia \\ ${ }^{2}$ James Cook University of North Queensland, Townsville, Queensland 4811, Australia
}

\begin{abstract}
A large-scale comparative study of 3 crown-of-thorns starfish (COTS) impacted reefs and 3 non-impacted (control) reefs in the central region of the Great Barrier Reef was undertaken. The principal objective was to investigate a long-term functional response of herbivorous fish to a potentially greater food resource in the form of increased abundances of turf algae on COTS affected reefs. Measurement of substratum cover and feeding ecology of Acanthurus nigrofuscus and Scarus frenatus was made on the windward reef slope of all reefs at a depth of 3 to $7 \mathrm{~m}$. Significantly higher abundances of turf algae in comparison with live coral cover occurred on COTS affected reefs, while the opposite pattern occurred on non-affected reefs. However, no obvious difference was detected in the overall dietary composition of $A$. nigrofuscus, variabllity being more apparent at a temporal scale. There was no difference in feeding rates of roving herbivores ( 2 species) between impacted and control reefs. Furthermore, one component of the turf algal assemblage (thick turfs) showed increases in abundance in winter on affected reefs, while on non-affected reefs, thick turfs did not exhibit this seasonal pattern. A similar trend was observed for Cyanophyta (blue-green algae) in the dietary assemblage of $A$. nigrofuscus, although different sampling times and lack of detailed knowledge of epilithic algal community (EAC) composition made direct correlations difficult to infer Whether this increased turf algal resource is prompting a numerical or growth response from herbivorous fishes is currently being investigated.
\end{abstract}

KEY WORDS: Herbivorous fish Crown-of-thorns starfish - Functional response - Feeding ecology Acanthurus nigrofuscus

\section{INTRODUCTION}

Patch creation or the release of space by natural disturbance has been identified to be as important as competitive interactions in regulating benthic communities (Connell 1978, White \& Pickett 1985, Reichelt 1988). Changes in benthic communities of coral reefs following environmental disturbances have been documented in Japan (Yamaguchi 1986, Sano et al. 1987),

- Present address: ICLARM Coastal Aquaculture Centre, PO Box 438, Honiara, Solomon Islands. E-manl: 1clarm@ffa.gov.sb the Caribbean (Lessios et al. 1983, Liddell \& Ohlhorst 1986, Hughes et al. 1987, Smith 1988, Carpenter 1990a), Hawaii (Walsh 1983), American Samoa (Wass 1987), Micronesia (Jones et al. 1976, Colgan 1987) and the Great Barrier Reef (GBR) (Done et al. 1988, 1991, Bradbury \& Mundy 1989). The most common response to patch creation on coral reefs has been the replacement of areas of live coral cover with epilithic algal communities (EACs), which represent the major food source of herbivorous fish on coral reefs (Hatcher \& Larkum 1983, Carpenter 1985, Klumpp et al. 1987. Scott \& Russ 1987). 
On the GBR, large-scale examples of patch creation occurred following outbreaks of crown-of-thorns starfish (COTS), which feed on hard live coral. Outbreaks have been documented for over 30 yr (Barnes \& Endean 1964, Endean 1973, Potts 1981, Moran 1986, Kenchington 1987 . Reichelt et al. 1990), with $70 \%$ of the reefs in the central region being affected in recent times (Moran et al. 1990). The net result of these outbreaks has been a large-scale shift in the relative proportions of the benthic biota. Cover of live coral has been substantially reduced, followed by an increase in percentage cover and biomass of algal turfs (Moran et al. 1985, Moran 1986, Bradbury \& Mundy 1989). In effect, this represented a large, additional food resource for herbivorous grazers. A similar phenomenon also occurred on a large scale on reefs in the Caribbean (Lessios et al. 1983, Bak 1985, Liddell \& Ohlhorst 1986, Hughes et al. 1987. Carpenter 1990a). In this instance, the cause was mass mortalities of the dominant benthic macrograzer Diadema antillarum. More importantly, both these natural disturbances have provided an excellent opportunity to test ecological hypotheses at a scale not possible under controlled experimental conditions

Arising from these impacts was the question: Do roving herbivorous fish communities respond in any manner to the increased turf algal resource? Previous studies have observed a tight coupling between roving grazers and their algal food resource (Carpenter 1986, Lewis 1986, Scott \& Russ 1987, Polunin \& Klumpp 1992). For example, Scott \& Russ (1987) demonstrated that short-term exclusion of large herbivorous grazers significantly altered the abundance of individual species and, consequently, the composition of the EAC. In all instances, herbivory by roving grazers was regarded as being fundamentally important in determining EAC composition. Thus, the immediate hypothesised response of roving herbivorous fish to the starfish outbreaks is a functional response. Has there been an increase in grazing intensity and/or a shift in diets? Carpenter (1990b) detected an immediate increase in grazing intensity of parrotfishes and surgeonfishes following Diadema antillarum mortalities in the Caribbean. This increased grazing pressure, however, fell back to pre-mortality levels within a few months. Following this, Carpenter (1990b) also observed an increase in numbers of parrotfish and surgeonfish, thus supporting the hypothesis that exploitative competition for the algal food resource had occurred prior to the mass mortalities of $D$. antillarum.
In this study, we compare substrate cover and feeding ecology of roving herbivores from 3 COTS affected and 3 control reefs within the central GBR to establish if there has been a functional response to a new food resource. Grazing rates were estimated for 2 representative species, a surgeonfish Acanthurus nigrofuscus and a parrotfish Scarus frenatus. In addition, dietary choice of $A$. nigrofuscus was examined in detail.

\section{MATERIALS AND METHODS}

Study sites. The study was conducted on 3 adjacent pairs of 'impacted/control' reefs in the central region of the GBR, Queensland, Australia (Fig. 1). These reefs were 'Grub/Centipede', 2 mid-shelf reefs, and 'Yankee/Bowl' and 'Dip/Coil', 4 outer-shelf reefs. All COTS affected reefs had experienced outbreaks in the last 5 to 7 yr (Moran et al. 1990). Sampling was carried out in a single topographic zone, the windward reef slope ( 3 to $7 \mathrm{~m}$ depth). This was the reef area most consistently experiencing starfish outbreaks (Moran 1986).

Substratum analysis. Data for substratum cover was collected along the same $45 \times 6 \mathrm{~m}$ transect utilised for the surveys of density and biomass of herbivorous fish (Hart et al. 1996 - this issue). Following completion of the fish counts, the recorder (A.M.H.) swam back along the transect and recorded substrate cover at a point at each $1 \mathrm{~m}$ interval. This resulted in 46 'point intercepts' ( 0 to $45 \mathrm{~m}$ ). To distinguish between intensively grazed surfaces and damselfish territories, turf algal cover was split into 2 arbitrary categories: $<1$ and

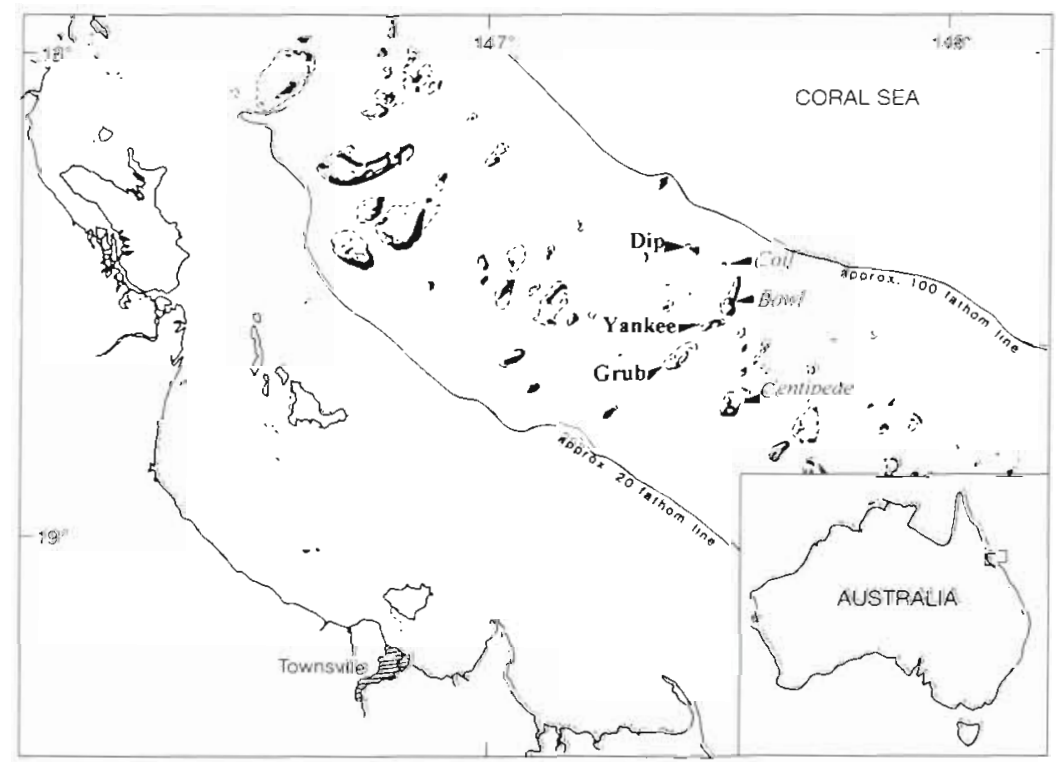

Fig. 1. Location of study reefs in the central region of the Great Barrier Reef. Crown-of-thorns starfish (COTS) impacted reefs in bold, non-impacted reefs in italics 
$\geq 1 \mathrm{~mm}$ (sensu Klumpp \& McKinnon 1989). This resulted in 7 physiognomic categories of substrate cover (1) fine turf algae ( $<1 \mathrm{~mm})$, (2) thick turf algae ( $\geq 1 \mathrm{~mm})$ (3) total turf algae (fine + thick), (4) coralline algae, (5) macro algae (mainly Halimeda sp.), (6) live hard coral cover, and (7) other, including biotic and abiotic substrata not falling into the former categories.

Sampling design and data analysis. Data for substrate cover and density and biomass of fish were collected simultaneously, allowing direct correlations between habitat type and fish abundance. Results from fish-habitat studies are reported in the companion paper (Hart et al. 1996). There were 3 sampling occasions (June 1991, January 1992, March 1993), 2 COTS status treatments (+ impacted, - non-impacted), and 3 reefs within COTS status. At each reef, on each occasion, 6 sites were selected and 3 replicate transects examined within each site. Data were analysed with a 4 -factor mixed model ANOVA. Sampling occasions and COTS status were treated as fixed and orthogonal, while reefs were orthogonal with occasions, but nested within COTS status. Cochran's test was carried out to test for heterogeneous variances. Tukey's pairwise comparison of means test was applied where the ANOVA detected a significant effect (Day \& Quinn 1989). Data for percentage substrate cover were transformed (arcsine, $p$ ) to normalise distributions (Zar 1984).

Feeding rates of herbivorous fish. The sample unit was a 5 min observation period for each individual (Montgomery et al. 1989), with the observers recording total number of bites taken during this time interval. Fork length of Acanthurus nigrofuscus was estimated visually, with each individual being assigned into $1 \mathrm{~cm}$ size classes. For Scarus frenatus, observations were made on initial phase females, as males are usually engaged in complex mating behaviour (D. R. Bellwood pers. comm.). All counts were taken between 10:00 and 16:00 h, when the fish were feeding actively (Bellwood \& Choat 1990).

Sampling design and data analysis. Seven replicate observations were taken at each of 8 sites within each reef. The data were analysed with a 3-factor mixedmodel ANOVA, with the factors being COTS status (fixed), Reef (nested within COTS status), and Sites (nested within reef and COTS status).

Dietary analysis. Ninety-four stomach samples of Acanthurus nigrofuscus were analysed for composition of diets, 53 from impacted reefs and 41 from nonimpacted reefs. Specimens were collected with spearguns and monofilament nets (15 mm mesh size) at all reefs on 2 separate occasions, April and October 1992 The stomach was dissected out and preserved in $70 \%$ seawater formalin. An adaptation of the method of Jones (1968) was utilised to quantify the diets (see laboratory procedure). Identifications follow those of Price \& Scott (1992) and Cribb (1983), with algal taxon being identified to the level of genus.

Laboratory procedure. The excised portion of the gut was split open and the contents washed into a petri dish This material was mixed with tap water and broken up with a dissecting needle. Using fine grade forceps (INOX 5), a 'clump' of this material was placed on a microscope slide, and further teased apart with the forceps and dissecting needle under low power. At a magnification of $\times 100,4$ areas of each slide were examined using an ocular micrometer with 25 intersection points. Any alga falling across one or more of these points of intersection was identified and counted. This procedure was repeated 3 times for each stomach sample. Thus, for each gut sample there was a total of 300 points of intersection (i.e. 3 slides $\times 4$ observations $\times 25$ points).

Data analysis. Multidimensional scaling (MDS) was utilised to delineate the dietary assemblage. The analysis was performed on the 15 most common algal taxa which comprised approximately $92 \%$ of the total diet composition. Normal or q-type analysis procedure (Field et al. 1982) was followed

Point intercept data were converted into proportions to obtain relative abundance estimates. Next, a dissimilarity matrix was constructed between samples using the standard Euclidean distance measure (Faith et al. 1990). MDS essentially seeks to scale (minimise) the dissimilarity matrix down to physical distances on a 2- or 3dimensional map, so that the between point distances have the same rank order as the higher dimensional dissimilarity matrix. Importantly, the final map is determined only within an arbritary orientation, location and scale and hence axis scales are omitted (Field et al. 1982).

Number of genera, divisions of turf algae, and the 9 most common taxa were subjected to a 2-fixed-factor ANOVA (Reefs, Time). All data were arcsine, $p$ transformed and a posteriori testing procedures were as for substratum analysis.

\section{RESULTS}

\section{Analysis of substratum cover}

Fine and thick turf algae were much higher in abundance on impacted reefs (Table 1; Fig. 2) and this pattern was maintained over time. Cover of fine turf increased consistently across occasions on affected reefs, however on control reefs there was an initial increase in fine turf from June 1991 to January 1992, then no change up to March 1993 (Fig. 2). This is evidenced by a significant interaction between Occasions and COTS status (Table 1). Cover of thick turf on impacted reefs was highest in June 1991, and similar 
Table 1. ANOVA results from the analysis of percentage cover of the 5 major physiognomic categories of substrate

\begin{tabular}{|c|c|c|c|c|c|c|c|c|c|c|}
\hline Source of variabiluty & df & MS & $F$ & $\mathrm{p}$ & MS & $F$ & $\mathrm{p}$ & MS & $F$ & $\mathrm{p}$ \\
\hline & & \multicolumn{3}{|c|}{ Fine turf $(<1 \mathrm{~mm})$} & \multicolumn{3}{|c|}{ Thick turf ( $\geq 1 \mathrm{~mm})$} & \multicolumn{3}{|c|}{ Total turf algae } \\
\hline Occasions & 2,90 & 0.125 & 45.1 & $\cdots$ & 0.021 & 2.01 & ns & 0.372 & 28.8 & $\cdots$ \\
\hline COTS status & 1,90 & 0.549 & 197 & $\cdots$ & 1.684 & 164.1 & $\cdots$ & 6.823 & 529 & $\cdots$ \\
\hline Reefs & 4.90 & 0.021 & 7.66 & $\cdots$ & 0.118 & 11.5 & $\cdots$ & 0.249 & 19.3 & $\cdots$ \\
\hline Occasions $\times$ COTS & 2,90 & 0.059 & 21.2 & $\cdots$ & 0.01 & 9.79 & $\cdots$ & 0.131 & 10.14 & $\cdots$ \\
\hline Occaslons $\times$ Reefs & 8,90 & 0.011 & 4.04 & $\cdots$ & 0.014 & 1.34 & ns & 0.044 & 3.38 & .. \\
\hline Sites & 90,216 & 0.0028 & 1.48 & • & 0.010 & 1.75 & $\cdots$ & 0.013 & 1.56 & . \\
\hline \multirow[t]{2}{*}{ Residual } & 216 & 0.0019 & & & 0.0019 & & & 0.0083 & & \\
\hline & & \multicolumn{3}{|c|}{ Live coral } & \multicolumn{3}{|c|}{ Coralline algae } & & & \\
\hline Occasions & 2,90 & 0.047 & 4.08 & $\cdot$ & 0.568 & 43.9 & $\cdots$ & & & \\
\hline COTS status & 1,90 & 4.55 & 399 & $\cdots$ & 0.003 & 1.87 & ns & & & \\
\hline Reets & 4,90 & 0.047 & 4.08 & $\cdot$ & 0.568 & 43.4 & $\cdots$ & & & \\
\hline Occasions $\times$ COTS & 2,90 & 0.014 & 1.26 & ns & 0.003 & 1.90 & ns & & & \\
\hline Occasions $\times$ Reels & 8,90 & 0.008 & 0.68 & $n s$ & 0.004 & 2.25 & $\cdot$ & & & \\
\hline Sites & 90,216 & 0.011 & 2.07 & $\cdots$ & 0.001 & 1.72 & $\cdots$ & & & \\
\hline Residual & 216 & 0.0055 & & & 0.0008 & & & & & \\
\hline
\end{tabular}
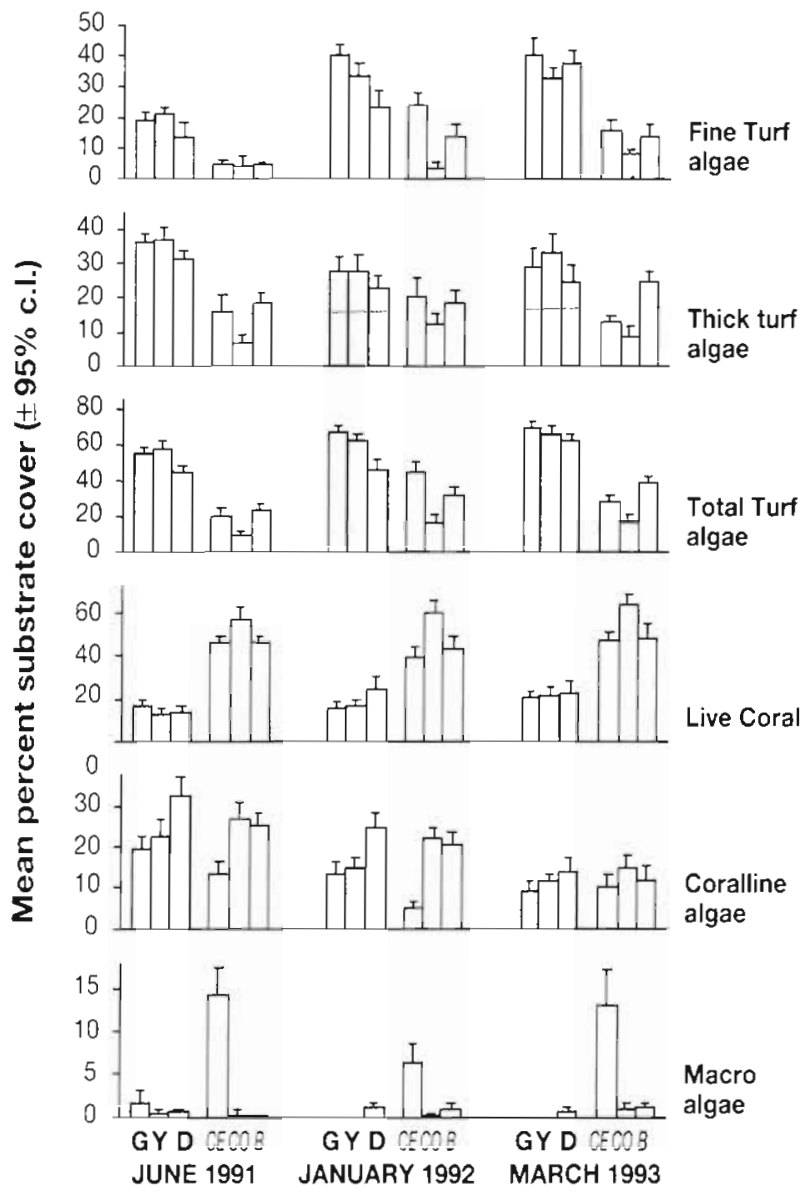

$\square$ impacted reefs $\square$ control reefs

Fig. 2. Mean \% cover of all physiognomic categories of substrate at impacted ( $\square$ ) and non-impacted reefs ( $\left.\square-{ }_{-}\right]$) during each sampling occasion. G: Grub, Y: Yankee, D: Dip, CE: Centipede, CO: Corl, B: Bowl in January 1992 and March 1993. On the other hand thick turf remained relatively consistent across all occasions on control reefs (Fig. 2). The pattern for total turf algae was similar to that of fine turf. Tukey's test distinguished Grub as having the highest cover of fine turf, Yankee and Dip showing the next highest, and Centipede, Coil, and Bowl having a similarly lower cover of fine turf (Fig. 2). In general, the pattern of live coral cover was opposite to that of turf algae, being highest on control reefs Centipede and Bowl and lowest on COTS impacted reefs (Fig 2).

\section{Feeding rates of Acanthurus nigrofuscus and Scarus frenatus}

No significant differences in bite rates of Acanthurus nigrofuscus or Scarus frenatus were detected between affected and non-affected reefs (Table 2). However, bite rate of $A$. nigrofuscus was significantly higher on Coil than all other reefs, except Dip (Table 2). This was directly related to size of $A$. nigrofuscus (Pearson, $\mathrm{r}=-0.278, \mathrm{n}=314, \mathrm{p}<0.001$ ), with smaller individuals exhibiting faster bite rates. Furthermore, a 1-way ANOVA detected significantly lower sizes of A nigrofuscus at Coil Reef $(F=85.17, p<0.001)$.

\section{Turf algal assemblage in the diet of Acanthurus nigrofuscus}

MDS ordinations showed no obvious separation of samples due to COTS status (Fig. 3a). Diets of Acanthurus nigrofuscus from non-impacted reefs tended to 
Table 2. ANOVA results and Tukey's test for analysis of feeding rates of Acanthurus nigrofuscus and Scarus frenatus (impacted reefs in bold; non-impacted reefs in italics). Underlines indicate Tukey's groups

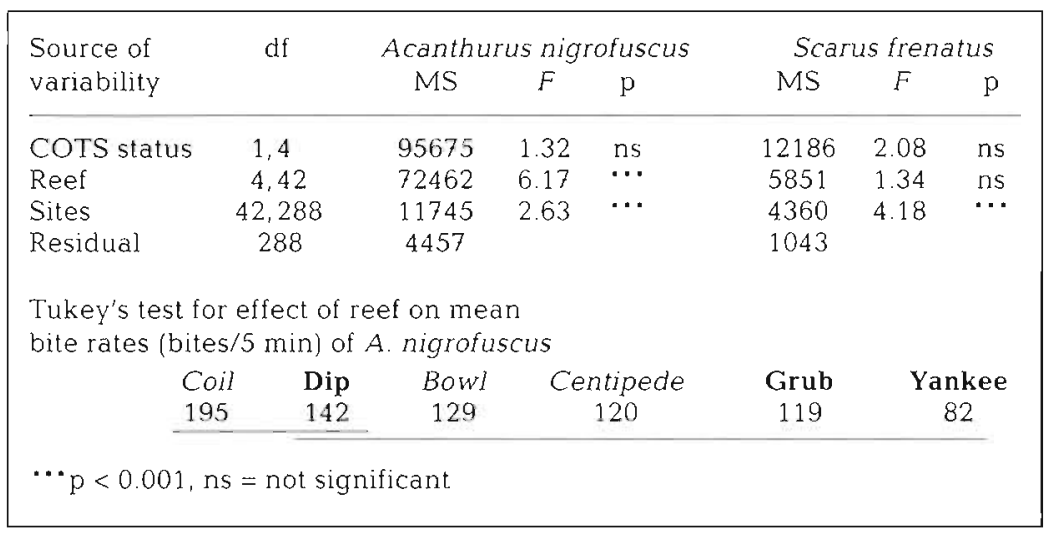

phyta than those from Yankee (Table 3; Fig. 4). Conversely, diets from Yankee contained a significantly higher percentage composition of Chlorophyta than Grub, Dip or Centipede, and this was consistent over both sampling times (Fig. 4).

\section{Analysis of diet by genera}

There was no significant difference in percentage diet composition between affected and control reefs for any genera. However, Enteromorpha sp. was more prevalent in diets from impacted reefs $(6.3 \pm 3.1)$ than non-impacted reefs $(2.8 \pm 1.1)$. Ceramium sp. and Entero- be more tightly clustered than those from impacted reefs, indicating a more uniform composition. In contrast, there was a clear temporal difference between the April and October samples (Fig. 3b). Hence, the variability in the dietary assemblage of $A$. nigrofuscus was most likely related to the time of year, and was least likely to result from the COTS status of the reef.

\section{Analysis of diets by divisions and generic richness}

A significantly higher number of genera $(11.9 \pm 0.7)$ occurred in the diets from April 1992, as opposed to October 1992 (10.4 \pm 0.7 ; Table 3). On impacted reefs (Grub, Yankee, Dip), Cyanophyta comprised a significantly greater percentage of diets in April, as opposed to October 1992 (Fig. 4). On control reefs (Centipede, Coil, Bowl), there was no difference in percentage composition of Cyanophyta between April and October 1992. Diet samples from Dip had a significantly higher percentage composition of Rhodo- morpha sp. were more common in April 1992 than October 1992, while Laurencia sp. exhibited the opposite pattern. Differences in percentage diet composition of genera between reef are summarised in Table 4.

\section{DISCUSSION}

In studies of localised regions of coral reefs, it is important to recognize that processes no longer evident may have been critical to the current distribution patterns (Reichelt 1988). This was well documented by Hughes (1989), who demonstrated the synergistic effects of 2 separate environmental disturbances on the benthic composition of a coral reef. The patchy nature of outbreaking COTS populations (Moran 1986) makes it difficult to establish whether a particular area of reef actually has a history of COTS disturbance. Since this posed potential problems in interpretation of within reef patterns, it was desirable to keep all analyses at the level of reefs to circumvent this.

The distinction between fine turf and thick turf was an important one, as differences in algal community structure have been shown to correspond with the frequency and intensity of herbivore-induced disturbance (Steneck 1988). Firstly, a decrease in cover of thick turfs occurred on impacted reefs from winter (June 1991) to summer (January 1992); however, this phenomenon did not occur on control reefs. In addition, there was some evidence of roving herbivores targeting this 'winter food' arising from dietary analysis of Acanthurus nigrofuscus. On affected reefs, Cyanophyta was in much higher
Fig. 3. Acanthurus nigrofuscus. MDS ordination plots of dietary assemblage.
Results are grouped by (a) COTS status, and (b) time
Aprit 1992

October 1992 
Table 3 Acanthurus nigrofuscus. AVOVA results for generic richness and the 4 principal divisions present in the diet

\begin{tabular}{|c|c|c|c|c|c|c|c|}
\hline Source of variability & df & MS & $F$ & $\mathrm{p}$ & MS & $F$ & $\mathrm{p}$ \\
\hline & \multicolumn{4}{|c|}{ Cyanophyta } & \multicolumn{3}{|c|}{ Rhodophyta } \\
\hline Time & 1,82 & 0.513 & 16.5 & $\cdots$ & 212.0 & 1.46 & ns \\
\hline Reef & 5,82 & 0.058 & 1.86 & ns & 398.4 & 2.74 & \\
\hline Time $\times$ Reef & 5,82 & 0.210 & 6.75 & $\cdots$ & 159.5 & 1.90 & ns \\
\hline \multirow[t]{2}{*}{ Residual } & 82 & & & & 145.3 & & \\
\hline & \multicolumn{4}{|c|}{ Chlorophyta } & \multicolumn{3}{|c|}{ Phaeophyta } \\
\hline Time & 1,82 & 1.52 & 0.013 & ns & 268.1 & 2.16 & ns \\
\hline Reef & 5,82 & 612.8 & 5.39 & $\cdots$ & 74.6 & 0.60 & ns \\
\hline Time $\times$ Reef & 5,82 & 79.8 & 0.69 & ns & 70.6 & 0.57 & ns \\
\hline Residual & 82 & 115.5 & & & 124.1 & & \\
\hline \multicolumn{8}{|c|}{ Number of genera } \\
\hline Time & 1,82 & 55.8 & 1.0 .23 & . & & & \\
\hline Reef & 5,82 & 7.23 & 1.33 & ns & & & \\
\hline Time $\times$ Reef & 5,82 & 8.44 & 1.55 & $\mathrm{~ns}$ & & & \\
\hline ResiduaI & 82 & 5.45 & & & & & \\
\hline
\end{tabular}

hypothesis could be tested by specifically identifying EAC composition on impacted and non-impacted reefs, and analysing the diets of grazers (specifically A. nigrofuscus) observed feeding on the substrate.

Impacted reefs increased in percentage cover of live coral from June 1991 to March 1993. This is possible evidence of a recovery; however, there was a concomitant increase in live coral on control reefs from January 1992 to March 1993. Certainly, the rate and direction of coral recovery is highly species-and disturbance-specific, depending more on local rather than on regional processes (Done et al. 1991). At the extreme scale, Done et al. (1988) predicted a recovery time in excess of $50 \mathrm{yr}$ for massive corals Porites spp. damaged by starfish outbreaks. In Thailand, sedimentation caused a $30 \%$ reduction

abundance in diets from autumn as opposed to spring, while no temporal difference occurred on non-affected reefs. Certainly, there is evidence of $A$. nigrofuscus switching diets to make use of winter blooms of Chlorophyta in the Red Sea (Fishelson et al. 1987). This

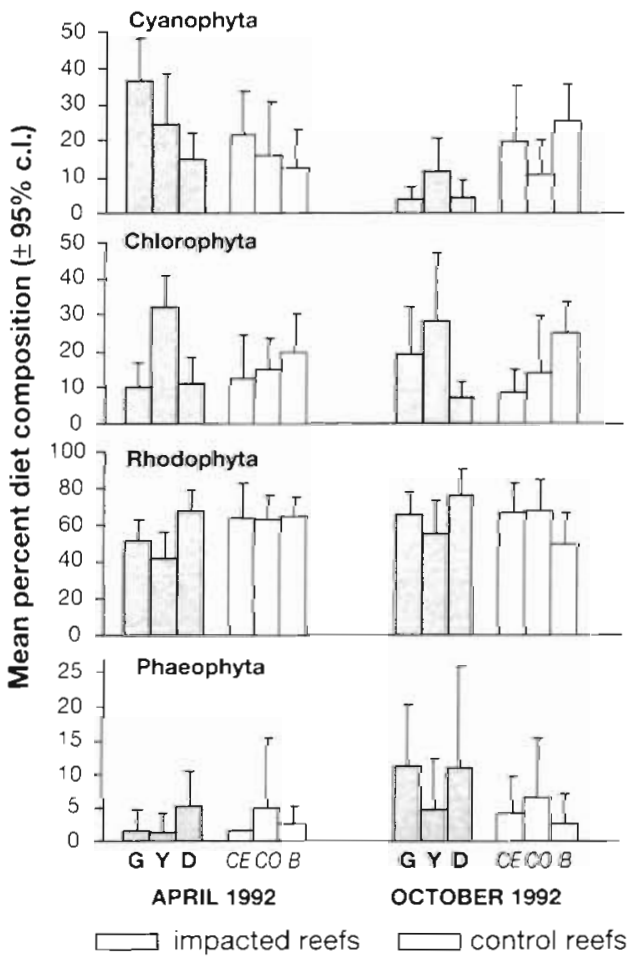

Fig. 4. Acanthurus nigrofuscus. Mean \% dietary composition (by division) at all impacted ( $\square$ ) and non-impacted ( $\square$ ) reefs during April and October 1992. Reefs as defined in Fig. 2 in live coral cover, yet percentage cover was back to predisturbance levels within 2 yr of the cessation of dredging (Brown et al. 1990). With respect to COTS outbreaks, a major factor influencing rates of recovery is the extent to which the spatial heterogeneity in reef structure has been damaged. Total collapse of the structural heterogeneity of a reef flat in Japan has resulted in very slow recovery rates (Sano et al. 1987). In contrast, reefs from Guam (Colgan 1987) had achieved pre-impact coverage of live coral within 12 yr of COTS outbreaks, despite coral cover being reduced to $<1 \%$ on most reefs. This was attributed to the persistence of the structural integrity of the reef matrix (Colgan 1987).

Two criteria were chosen as providing evidence of an additional algal food resource. Firstly, cover of algal turfs on COTS impacted reefs must be greater than on non-impacted reefs. Secondly, this pattern must be maintained over the 2 yr sampling period. Results of this study show this to be clearly the case, and subsequent investigations were devoted to answering the question: Have Acanthurus nigrofuscus and Scarus frenatus exhibited a functional response to this available food resource?

\section{Feeding rates of Acanthurus nigrofuscus and Scarus frenatus}

No differences in bite rates of either species was detected between COTS affected and control reefs. Carpenter (1990b) did detect a short-term feeding response from roving herbivores to increases in biomass of turf algae. This, however, lasted only a few 
Table 4. Tukey's test for the effect of reefs (reefs as defined in Fig. 2) on percentage diet composition of 5 common genera of algal turfs (R: Rhodophyta; CH: Chlorophyta). Means (\% composition) are shown and underlines indicate Tukey's groups

\begin{tabular}{|c|c|c|c|c|c|c|c|c|c|c|c|c|c|c|c|c|c|}
\hline \multicolumn{6}{|c|}{ Polysiphonia $(\mathrm{R})$} & \multicolumn{7}{|c|}{ Cladophora $(\mathrm{CH})$} & \multicolumn{5}{|c|}{ Enteromorpha $(\mathrm{CH})$} \\
\hline $\mathrm{CO}$ & $\mathrm{Y}$ & $\mathrm{D}$ & $C E$ & $B$ & G & $\mathrm{Y}$ & CO & $B$ & $\mathrm{D}$ & $C E$ & G & $\mathrm{Y}$ & G & $C E$ & $\mathrm{CO}$ & $B$ & D \\
\hline 18.0 & 17.2 & 16.3 & 8.7 & 7.2 & 6.6 & 16.3 & 10.4 & 8.9 & 4.9 & 3.3 & 2.1 & 1.2 .6 & 5.9 & 3.4 & 2.7 & 2.4 & 1.6 \\
\hline \multicolumn{6}{|c|}{ Herposiphonia (R) } & \multicolumn{6}{|c|}{ Caulerpa $(\mathrm{CH})$} & & & & & & \\
\hline $\mathrm{CO}$ & $\mathrm{D}$ & $B$ & $\mathrm{Y}$ & $C E$ & G & $B$ & G & $C E$ & $\mathrm{D}$ & $\mathrm{CO}$ & $\mathrm{Y}$ & & & & & & \\
\hline 10 & 5.2 & 3.8 & 2.4 & 2.4 & 1.6 & 8.8 & 7.3 & 3.5 & 2.1 & 1.6 & 0.9 & & & & & & \\
\hline
\end{tabular}

months before feeding rates returned to prior-impact levels (Carpenter 1990b). Furthermore, in the present study the opposite trend to the predicted response occurred, with both Acanthurus nigrofuscus and Scarus frenatus exhibiting highest mean feeding rates on non-impacted reefs.

Coil Reef experienced the highest mean bite rates of Acanthurus nigrofuscus and Scarus frenatus. This was a function of size of fish as small fish bite faster and Coil had a significantly lower mean size of $A$. nigrofuscus than all other reefs. Furthermore, Coil exhibited the lowest mean percentage cover of both fine and thick turfs on all occasions (Fig. 2). Thus, in addition to being smaller, the fish simply may have had to feed more rapidly on Coil to obtain their nutritional requirements.

\section{Diets of Acanthurus nigrofuscus}

This is the first instance of quantification of diets of Acanthurus nigrofuscus on the GBR. Utilising substrate analysis and availability of algal taxa, Scott \& Russ (1987) identified the dominant turf algal taxa which would be expected to be major components of the diets of roving herbivores (e.g. Enteromorpha, Polysiphonia, Cladophora sp.). Indeed, all of these algae were common in the diets of $A$. nigrofuscus.

Little difference in composition of diets existed between impacted and non-impacted reefs, variability being more apparent on a temporal scale. This concurred with results from the analysis of feeding rates. Diets of Acanthurus nigrofuscus from control reefs did, however, show evidence of a more uniform composition. The present study also found some evidence of high abundance of Chlorophyta in the diet in autumn, with Enteromorpha $\mathrm{sp}$. being more abundant in diets from April.

Although the trend of winter high abundances and summer low abundances of Cyanophyta (from diets) and thick turfs (from substrate) on impacted reefs appear related, it is difficult to infer direct correlations due to different sampling times (June and January thick turfs; April and October diets). Moreover, in a companion paper, Hart et al. (1996) showed that on impacted reefs, roving herbivores may be avoiding areas of thick algal turfs. The proportion of thick turfs represented by Cyanophyta is unknown, although it is probably substantial. Wilkinson et al. $(1984,1985)$ reported that blue-green algae (Cyanophyta) were more abundant on grazed than on ungrazed substrata, while Scott \& Russ (1987) demonstrated the opposite pattern.

In conclusion, there was primary evidence of an additional food resource on affected reefs, expressed as significantly higher percentage cover of algal turfs compared to control reefs. However, no evidence of a functional response in terms of differences in grazing intensity by an acanthurid and scarid was detected. Limited evidence of a functional response in terms of composition of diets of Acanthurus nigrofuscus was observed. Both the thick turf algal assemblage and Cyanophyta in the diets of $A$. nigrofuscus showed a temporal change on impacted reefs, but did not exhibit this trend on nonimpacted reefs. However, Hart et al. (1995) demonstrated negative correlations between roving herbivores and thick turf algae on impacted reefs. Implications of this are discussed in related studies on grazing fish population densities and correlations between fish and habitat structure (Hart et al. 1996)

Acknowledgements. This project was funded by a COTSREC (Crown-of-Thorns Starfish Research Committee) Ph.D. scholarship to A.M.H., administered by the Great Barrier Reef Marine Park Authority, with logistical support from AIMS. The authors thank Garry Russ for helpful suggestions, and the many volunteer research assistants, principally Rod Forbes and Dave Hocking. Ian Price assisted greatly with taxonomic identufications of turf algae. Finally, special thanks to the crew of the RV 'Harry Messel', who made the field excursions safe and enjoyable, and to the anonymous referees for their pertinent comments. This contribution no. 726 from the Australian Institute of Marine Science.

\section{LITERATURE CITED}

Bak RPM (1985) Recruitment patterns and mass mortalities in the sea-urchin Diadema antillarum. Proc 5th int Coral Reefs Congr 5:267-272

Barnes J, Endean R (1964) A dangerous starfish - Acanthaster planci (Linne). Med J Aust 1(16):592-593 
Bellwood DR, Choat JH (1990) A functional analysis of grazing in parrotfishes (family Scaridae): the ecological implications. Environ Biol Fish 28:189-214

Bradbury RH, Mundy CN (1989) Large scale shifts in biomass of the Great Barrier Reef ecosystem. In: Sherman $K_{\text {, }}$ Alexander L (eds) Biomass and geography of large marine ecosystems. Westfield, Boulder, CO, p 143-167

Brown BE, LeTissier MDA, Scoffin TP, Tudhope AW (1990) Evaluation of the environmental impact of dredging on intertidal coral reefs at Ko Phuket, Thailand, using ecological and physiological parameters. Mar Ecol Prog Ser 65(3): $273-281$

Carpenter RC (1985) Sea-urchin mass mortality: effects on reef algal abundance, species composition and metabolism and other coral reef herbivores. Proc 5th int Coral Reefs Congr, Tahiti 4:53-60

Carpenter RC (1986) Partitioning herbivory and its effects on coral reef algal communities. Ecol Monogr 56:345-363

Carpenter RC (1990a) Mass mortality of Diadema antillarum. I. Long-term effects on sea urchin population dynamics and coral reef algal communities. Mar Biol 104:67-77

Carpenter RC (1990b) Mass mortality of Diadema antillarum. II. Effects on population densities and grazing intensity of parrotfishes and surgeonfishes. Mar Biol 104:79-86

Colgan MW (1987) Coral reef recovery on Guam (Micronesia) after catastrophic predation by Acanthaster planci. Ecology 68(6): $1592-1605$

Connell JH (1978) Diversity in tropical rain forests and coral reefs. Science 199:1302-1310

Cribb AB (1983) Marine algae of the southern Great Barrier Reef. Part I. Rhodophyta. Handbook No. 2, Australian Coral Reef Society, Brisbane

Day RW, Quinn GP (1989) Comparisons of treatments after an analysis of variance in ecology. Ecol Monogr 59(4): $433-463$

Done TJ, Dayton PK, Dayton AE, Steiger R (1991) Regional and local variability in recovery of shallow coral communities: Moorea, French Polynesia and central Great Barrier Reef. Coral Reefs 9:183-192

Done TJ, Osborne K, Navin KF (1988) Recovery of corals postAcanthaster. progress and prospects. Proc 6th int Symp Coral Reefs 2:137-143

Endean R (1973) Population explosions of Acanthaster planci and associated destruction of hermatypic corals in the Indo-West Pacific Region. In: Jones OA, Endean R (eds) Biology and geology of coral reefs. Vol 2. Academic Press, New York, p 389-438

Faith DP, Humphrey CL, Dostine PL (1990) Statistical power and BACI designs in biological monitoring: comparative evaluation of measures of community dissimilarity based on benthic macro-invertebrate communities in Rockhole Mine Creek, Northern Territory, Australia. Aust J mar Freshwat Res 42:589-602

Field JG, Clarke KR, Warwick RM (1982) A practical strategy for analysing multispecies distribution patterns. Mar Ecol Prog Ser 8:37-52

Fishelson L, Montgomery WL, Myrberg AA (1987) Biology of surgeonfish Acanthurus nigrofuscus with emphasis on changeover in diet and annual gonadal cycles. Mar Ecol Prog Ser 39:37-47

Hart AM, Klumpp DW, Russ GR (1996) Response of herbivorous fishes to crown-of-thorns starfish Acanthaster planci outbreaks. II. Density and biomass of selected species of herbivorous fish and fish-habitat correlations. Mar Ecol Prog Ser 132:21-30

Hatcher BG, Larkum AWD (1983) An experimental analysis of factors controlling the standing crop of the epilithic algal community on a coral reef. J exp mar Biol Ecol 69: 61-84

Hughes TP (1989) Community structure and diversity of coral reefs; the role of history. Ecology 70:275-279

Hughes TP, Reed DC, Boyle MJ (1987) Herbivory on coral reefs: community structure following mass mortalities of sea urchins. J exp mar Biol Ecol 113:39-59

Jones RS (1968) A suggested method for quantifying gut contents in herbivorous fishes. Micronesica 4:369-371

Jones RS, Ranclall RH, Wilder MJ (1976) Biological impact caused by changes on a coral reef. United States Environmental Protection Agency Publication, EPA-600/3-76-027

Kenchington R (1987) Acanthaster planci and the management of the Great Barrier Reef. Bull mar Sci 41:552-560

KIumpp DW, McKinnon AD (1989) Temporal and spatial patterns in the primary production of a coral reef epilithic algal community. J exp mar Biol Ecol 131:1-22

Klumpp DW, McKinnon AD, Daniel. P (1987) Damselfish territories: zones of high productivity on coral reefs. Mar Ecol Prog Ser 40:41-51.

Lessios HA, Glynn PW, Robertson DR (1983) Mass mortality of coral reef organisms. Science 222:715

Lewis SM (1986) The role of herbivorous fishes in the organisation of a Carribean reef community. Ecol Monogr 56: $183-200$

Liddell WD, Ohlhorst SL (1986) Changes in benthic community composition following the mass mortality of Diadema at Jamaica. J exp mar Biol Ecol 95:271-278

Montgomery WL, Myrberg AA, Fishelson L (1989) Feeding ecology of surgeonfishes (Acanthuridae) in the northern Red Sea, with particular reference to Acanthurus nigrofuscus (Forsskâl). J exp mar Biol Ecol 132:179-207

Moran PJ (1986) The Acanthaster phenomenon. Oceanogr mar B1ol A Rev 24:379-480

Moran PJ, Bradbury RH, Reichelt RE (1985) Mesoscale studies of the crown-of-thorns/coral interaction: a case history from the Great Barrier Reef. Proc 5th int Coral Reefs Congr 5:321-326

Moran PJ, De'ath G, Baker VJ, Bass DK, Christie CA, Johnson DB, Miller IR, Miller-Smith BA, Mundy CN, Thompson AA (1990) Broadscale surveys of crown-of-thorns starfish and corals along the Great Barrier Reef: 1982-1990. Australian Institute of Marine Science, Townsville

Polunin NVC, Klumpp DW (1992) AlgaJ. food supply and grazer demand in a very productive coral-reef zone. J exp mar Biol Ecol 164:1-15

Potts DC (1981) Crown of thorns starfish: man-induced pest or natural phenomenon? In: Kitching $R L_{\text {, J Jones }} R E$ (eds) The ecology of natural pests. CSIRO, Melbourne, p 55-86

Price IR, Scott FJ (1992) The turf algal flora of the Great Barrier Reef. I. Rhodophyta. James Cook University, Townsville

Reichelt RE (1988) Space and structure effects on coral reefs. Proc 6th int Symp Coral Reefs 1:235-242.

Reichelt RE, Bradbury RH, Moran PJ (1990) Distribution of Acanthaster planci outbreaks on the Great Barrier Reef between 1966 and 1989. Coral Reefs 9:97-103

Sano M, Shimizu M. Nose Y (1987) Long term effects of the destruction of hermatypic corals by Acanthaster planci infestation on reef fish communities at Inomote Island, Japan. Mar Ecol Prog Ser 37:191-199

Scott FJ, Russ GR (1987) Effects of grazing on species composition of the epilithic algal community on coral reefs of the central Great Barrier Reef. Mar Ecol Prog Ser 39: $293-304$

Smith SR (1988) Recovery of a disturbed reef in Bermuda influence of reef structure and herbivorous grazers on 
algal and sessile invertebrate recruitment. Proc 6th int Symp Coral Reefs 2:267-272

Steneck RS (1988) Herbivory on coral reefs: a synthesis. Proc 6th int Symp Coral Reefs 1:37-49

Walsh WJ (1983) Stability of a coral reef fish community following a catastrophic storm. Coral Reefs 2:49-63

Wass RC (1987) Influence of Acanthaster-induced coral kills on fish communities at Fagatele Bay and at Cape Larsen. In: Birkeland C, Randall RH, Wass RC, Smith BD, Wilkins $S$ (eds) Biological resource assessment of the Fagatele Bay National Marine Sanctuary. NOAA technical memoranda NOS MEMD 3. United States Department of Commerce, p 193-209

White PS, Pickett STA (1985) Natural disturbance and patch dynamics: an introduction. In: White PS, Pickett STA (eds)

This article was submitted to the editor
The ecology of natural disturbance and patch dynamics Academic Press, Orlando, p 3-13

Wilkinson CR, Sammarco PW. Trott LA (1985) Seasonal and fish grazing effects on rates of nitrogen fixation on coral reefs (Great Barrier Reef, Australia) Proc 5th int Coral Reefs Congr, Tahiti 4:61-65

Wilkinson $(: R$, Williıms D McB, Sammarco PW, Hogg RW, Trott LA (1984) Rates of nitogen fixation on coral reefs across the continental shelf of the central Great Barrier Reef. Mar Bıol 80:255-262

Yamaguch M (1986) Acanthaster planci infestations of reefs and coral assemblages in Japan: a retrospective analysis of control efforts. Coral Reefs 5:23-30

Zar JH (1984) Biostatistical analysis, 2nd edn. Prentice-Hall, Englewood Cliffs, NJ

Manuscript first received: November 2, 1994 Revised version accepted: September 14, 1995 